\title{
Pedro Arrupe, renovador de la vida religiosa
}

\author{
Ignacio Ellacuría \\ Centro de Reflexión Teológica, \\ San Salvador, El Salvador.
}

Tras muchos años de entrega testimonial de una vida consumida en favor de la renovación de la vida religiosa, el padre Pedro Ampe ha muerto. Han sido ajios en que personas como el padre Ignacio Elacuría han podido ir haciendo un balance del importante papel jugado por el exsuperior general de la Compañía de Jesús, sobre todo para el trabajo realizado por los jesuitas de Centroamérica en los úlimos años. Fruto de dicho balance es el presente artículo, aparecido hace unos anos en el libro publicado por la editorial Sal Terrae, Pedro Arrupe. Ast lo vieron. Nos parece justificado y provechoso el publicar ahora estas reflexiones hechas por Ignacio Ellacuría, testigo también, mediante su palabra y su vida, de la defensa de la fe y de la justicia.

No es mi propósito hacer un estudio exahustivo de las ideas del padre Amupe sobre la vida religiosa (punto, por otra parte, de gran interés teológico, pues de sus numerosos escritos podrian sacarse orientaciones de mucha novedad y profundidad). Tampoco pretendo hacer un recuento de lo que fue su modo real de vivir la vida religiosa y su forma de dirigirla en las distintas etapas de su vida. Lo que más bien intento es descubrir, desde una perspectiva testimonial, algunos de los elemen os que considero esenciales para explicar hasta qué punto y por qué el padre Arrupe ha sido, de hecho, un gran renovador de la vida religiosa en general, a la que ha vuelto a poner evangélicamente a la altura de las exigencias de nuestro tiempo.

Escribo desde Centroamérica y, más concretamente, desde El Salvador. Ni Centroamérica ni El Salvador son lugares puramente geograficos. Son lugares históricos en los que se están debatiendo problemas fundamentales para la humanidad verdadera y total, que no cabe confundir con lo que entienden por "humanidad universal" los que hablan desde la perspectiva, mucho más loca- 
lizada y particularizada, de los países absolutamente minoritarios que van a la cabeza del desarrollo económico. La humanidad es otra cosa, y en el momento actual está mayoritariamente constituida por los más de tres mil millones de hombres que viven en unas condiciones materiales que hacen prácticamente imposible una vida realmente humana. Esta consideración, como luego explayaremos, es esencial en la visión misionera de la vida religiosa del padre Arupe y constibuye uno de los polos en que se va a apoyar su concepción de la misma.

\section{El Padre Arrupe visto desde la crisis centroamericana}

Conviene recordar aquí cómo ha sido América Latina, y en especial Centroamérica, uno de los asuntos más "escandalosos" de los últimos affos del generalato del padre Arrupe, hasta el punto de que muchos observadores externos al problema consideraron que en este asunto radicaba el fundamento de las discrepancias de la Santa Sede con el General de la Compañía de Jesús, llegando a constituirse en una de las causas principales de la intervención extraordinaria de Juan Pablo II en el gobiemo ordinario de la orden, tal como lo quiso san Ignacio. El padre Arrupe habría sido "flojo" a la hora de enderezar los excesos de unos jesuitas que, apelando a la opción preferencial por los pobres como a un criterio decisivo de la vida cristiana en general y de la vida religiosa en particular, $y$ haciendo de la lucha por la justicia un elemento esencial de la evangelización, se habrian comprometido de tal manera con las mayorias populares -y eventualmente con las organizaciones populares - que habrian terminado politizando la fe, marxistizando la vida religiosa y predicando la violencia como la vía más cristiana para instaurar el reino de Dios.

¿Es ésta la recta interpretación de lo que ha pasado en Centroamérica durante el generalato del padre Arrupe? Responder a esta cuestión es importante no sólo para aclarar puntos esenciales de su dirección de la Companía de Jesús como superior general, sino para profundizar en aquello que hace de él un vigoroso renovador de la vida religiosa. Y es que el caso de Centroamérica inplica el encuentro de una respuesta evangélica que ha hecho de la vida religiosa en el continente algo realmente operante e inspirador, algo que ha conmocionado positivamente al resto de la Iglesia, y negativamente a quienes pensaban que los religiosos - y la propia Iglesia - están para mantener el status quo y para dar formación no comprometida a sus hijos y familiares. Dejo de lado, por tanto, aquel otro tipo de acusaciones que responsabilizan al padre Amupe de la secularización de la Companía de Jesús en paises más desarrollados o en sectores religiosos de los países menos desarrollados que viven como si se encontraran en paises opulentos. Esto plantea otros problemas que poco tienen que ver con lo que en la inspiración y orientación del padre Arrupe habla de innovador para la vida religiosa. Allf donde el esplritu por él despertado no se encarnó adecuadamente en las exigencias de las mayorías populares, en la opción preferencial por los pobres y en la lucha por la justicia, all la vuelta al mundo pudo 
convertirse en una conformación con los valores del mundo, más o menos disimulada por prácticas ritualistas o por confesiones verbales de la fe, lo cual puede resultar, a la larga, tolalmente insatisfactorio para muchos.

Volvamos, pues, a Centroamérica como ejemplo de lo que ocurrió en otras partes de América Latina y en otros muchos lugares del tercer mundo, especialmente de India y de Filipinas.

Cuando, golpeado ya por su enfermedad (en la que tanto tuvieron que ver, junto con su ingente pero sosegada actividad, los disgustos y tensiones suscitados en el entomo romano), acudí a visitarle en la enfermería de la curia generalicia, el padre Arrupe, casi balbuciente, me dijo: "Nosotros - se refería a él mismo y a los jesuitas centroamericanos - empezamos separados y alejados, pero poco a poco fuimos acercándonos; sufrimos mucho, pero al fin llegamos a entendemos y lograr un elevado punto de acuerdo; Dios así lo quiso...", y movía sus brazos de abajo arriba, formando como un arco, abierto en su parte inferior y casi cerrado en su parte superior. Así fue en el largo período de 1969 a 1976. Conviene insistir en ello, porque puede parecer que el padre Arupe no sabía exigir, no sabía dar órdenes, no sabia intervenir, en definitiva: no ejercía la autoridad. Esto es absolutamente falso en el caso de Centroamérica, donde tomó medidas muy drásticas y muy eficaces; pero las tomo como corresponde a un verdadero seguidor de Jesús y no como las toman los señores de este mundo. Sólo conozco a otro hombre egregio que se le pueda comparar en el modo de ejercer la autoridad evangélica. Es otro mártir, monsefior Oscar Amulfo Romero, tan amigo del padre Amupe y tan consolado por éste en sus diffciles viajes a Roma. Cada vez más, bastaba con que el padre Amupe pidiese algo a los jesuitas centroamericanos - por más que a éstos no les pareciera acertada la decisión, por más que supusiese grandes sacrificios - para que no sólo lo acatasen, sino que lo pusieran gustosamente en práclica con verdadera obediencia de juicio y de sentimiento. Esto se refiere tanto a casos personales en los que a él le pareció bien cambiar a consultores o superiores, como a directrices de acción en busca de una más explícita espiritualidad o un más asiduo uso de los sacramentos o de determinadas prácticas apostólicas. Muchas cosa se cambiaron en los planes de formación o en los planes apostólicos que se proponian desde Centroamérica por las directrices que venían de Roma. Y ello no porque en contrapartida se aceptasen desde Roma novedades que desde Centroamérica se proyectaban en una especie de compromiso, sino porque se habia encontrado conjuntamente la voluntad de Dios mediante un juego de representación y discemimiento realizado, eso $\mathrm{s}$, a la luz de las más estrictas exigencias evangélicas y de lo que se había concretado como llamada de Dios a la Compantía en la Congregación General XXXII, entendida desde el clamor por la justicia y la liberación de las mayorías más empobrecidas del mundo entero.

¿En qué estaban las diferencias y hacia dónde fueron las coincidencias? 
Por impulso e inspiración de la Conferencia de Medellín (1968), donde ya se habla hecho presente de manera predominante la teología de la liberación, responsable y críticamente asumida en los documentos oficiales emanados de aquella asamblea, la entonces Viceprovincia de Centroamérica habla empezado a marchar por esas mismas líneas de Medellín y de la teología de la liberación. Esto ocurra cinco affos antes de que la Congregación General XXXI elaborara el Decreto cuarto. Lo que ocurrió en gran parte de la Companía gracias al choque que supuso la nueva orientación de aquella congregación, había sucedido antes en Centroamérica.

Lo que más llamaba la atención, en un primer momento, era la "división de los ánimos". El padre Arrupe llegó a decir que en ninguna otra parte de la Companía habla tal "división de los ánimos" entre los que propugnaban la línea de la liberación y los que se inscriblan en la línea del desarrollo; entre quienes sostenían la necesidad operativa de una opción preferencial por los pobres y quienes defendían más bien un amor universal no parcializado; entre quienes inclúan como elemento esencial de la evangelización la promoción de la justicia y quienes pensaban que en esta orientación se estaba desvirtuando el mensaje espiritual de la fe cristiana. Era en El Salvador donde más enconada se hacía la dispula, resuelta definitivamente, por cierto, tras el martirio del padre Rutilio Grande (1977) y la vida y muerte de monsenor Romero (1977-1980) como arzobispo de San Salvador. Todavía en la Congregación General XXXIII se sostendría que segufa siendo muy importante superar la división de los ánimos, surgida fundamentalmente de esta misma problemática, lo cual iba ligado a la sospecha de la Santa Sede sobre la Congregación General XXXII y a la intervención directa del Papa con el nombramiento del padre Dezza.

En la explicación de la división de los ánimos era donde estaban las diferencias fundamentales, lo cual llevó a escribir diversos trabajos sobre lo que es el conflicto en la Iglesia: por qué se da y en qué medida es necesario que se dé, sin que el conflicto tenga por qué llevar a una separación o a la creación de dos Iglesias paralelas o, para el caso, dos Companias de Jesús, como fue la intención de algunos de aquellos -ninguno en Centroamérica de modo directo y expreso- que consideraban que en el esfuerzo renovador de Amupe se estaba poniendo en peligro lo sustancial de la Comparía de Jesús. En el caso de Centroamérica, tal vez Amupe propendiera entonces a una explicación excesivamente idealista 0 , al menos, espiritualista; es decir, no poniendo la ráz de la división en una opción primordial que situaba a los pobres y su liberación integral en su punto de mira. Esta opción primordial, en el caso de Centroamérica, y en particular de El Salvador, llevaba no sólo a romper con orientaciones generales del apostolado anterior, sino a enfrentarse con las clases más poderosas, los gobiemos y los aparatos militares y de seguridad, que se sentian abandonados y aun denunciados por quienes hasla entonces habían sido, si no sus protectores, sí sus allegados, en la buena intención de que era posible su cambio y conversión 


\section{personal.}

Más en particular, la inseparabilidad del anuncio de la fe y la promoción de la justicia llevaba a teorías y prácticas encontradas. Poco a poco, Amupe fue entendiendo cuán esencial era al anuncio de la fe la apuesta por las mayorías populares para, desde ellas, renovar la misma fe de modo que se integraran en ella las obras, sin las que la fe no justifica, que eran -en nuestro caso histórico de modo excepcional - las obras de la justicia liberadora. En esos dos puntos esenciales de privilegiar a las mayorias pobres y oprimidas del mundo entero y de captar la necesidad de la promoción de la justicia (denuncia de la injusticia y anuncio de la justicia) es donde la concepción de Arrupe de la vida religiosa experimentó un mayor vuelco 0 , al menos, una encarnación y concreción absolutamente nuevas. Son cualitativamente distintos desde un punto de vista histórico -aunque sean el mismo espíritu y la misma espiritualidad to subyacente- el intento de ayudar a las víctimas de las primeras y únicas bombas atómicas lanzadas contra la población civil, en una masacre sin precedentes, y el intento de desenmascarar a los verdaderos causantes de la violencia y el consiguiente esfuerzo por hacer que las víctimas de la violencia y la injusticia se conviertan en sujetos de su propia liberación.

Tras el pecado personal se había descubierto el pecado histórico con su conponente estructural. No solo habia que convertir a personas, sino que habia que transformar estructuras, porque el pecado podí surgir del corazón del hombre, pero se objetivaba en estructuras e instituciones, fruto del pecado y causas de males sin fin que contradicen objetivamente la voluntad del Padre e impiden el advenimiento del reino de Dios. Para poder tratar el pecado personal bastaba con la palabra de Dios, ayudada algunas veces por el talento psicológico y aun por cierta preparación pastoralista; para poder tratar el pecado estructural habla que echar mano, desde luego, de la palabra de Dios, pero se necesitaba además de arduos análisis sociales y, eventualmente, de colaboración con aquellas organizaciones que se levantaban contra la injusticia estructural y prometían, revolucionariamente, cambios fundamentales en favor de las mayorias populares.

De este modo se daba paso a una nueva espiritualidad que ponía su centro en la misión y no tanto en la institución. El "contemplativo en la acción" volvía a cobrar nueva vida, una vez que se habia encontrado la acción donde realmente estaba la voluntad de Dios, y con ello, se había definido el lugar de su encuentro. No era cualquier accion, sino la acción que, desde la fe, trataba de ponerse al lado de los pobres en afecto y en efecto, pero no como puro testimonio de encamación, sino como levadura que les ayudase a crecer y a ponerse en marcha.

Estos puntos, que eran contribución de la periferia hacia Roma, fueron madurando gracias a las orientaciones que venían de Roma. Amupe insistió y logro que no se cayera, al menos definitiva y dogmáticamente, en las exagera- 
ciones que amenazaban a esta nueva orientación de la vida religiosa jesuítica que, en vez de canalizar el anuncio de la fe y su espiritualidad correspondiente hacia la mejora del (des)orden establecido desde los que estaban al frente de él, lo canalizaba hacia el cambio del mismo desde los que eran sus victimas. Las exageraciones en las que él vela mayor peligro eran la parcialización y politización de la fe, el olvido de la dimensión personal y espiritualista de la fe y la evangelización, el entrar en el juego de la lucha de clases con la justificación de la violencia y la tendencia a enrolarse en organizaciones políticas partidistas. No se cansaba de advertir de estos peligros e iluminar estos problemas, pero siempre depositando su confianza en quienes trabajaban sobre el terreno y habian demostrado su fidelidad al Dios de Jesús, a la Iglesia y a la Compatía, siempre pronto a creer y confiar en quienes, con libertad, pero con humildad, le hacian ver puntos de vista complementarios de los que se alcanzaba a ver desde la lejania y la "universalidad" de Roma. Gracias a esta confianza y gracias a sus avisos e inspiraciones, se hizo cada vez mayor hincapié en la espiritualidad y aun en las prácticas espirituales; se procuró que la reflexión teológica sobrepasara los límites de los intereses inmediatos para acercarse a los grandes temas clásicos de "Dios", "Cristo", "la Iglesia", las "relaciones del hombre con Dios", etc.; se evito, por lo general, todo tipo de afiliación política estrictamente tal; se evitó la aceptación acrítica de la violencia y se fue sumamente cuidadoso en el uso del análisis marxista, tal como él lo recomendó en su estudio sobre este punto.

Así se entiende cómo, desde sustanciales diferencias, los jesuitas de Centroamérica y el padre Amupe fuimos alcanzando un muy alto grado de consenso, al que se llegó por crecimiento y no por imposición. Todos aprendimos en el proceso y todos sufrimos con él; pero los resultados fueron buenos: donde apenas habja vocaciones nativas, empezaron a florecer estas de un modo extraordinario; donde la reflexión teológica propia era casi nula, empezó a surgir un movimiento teológico importante; donde el conjunto de las mejores fuerzas se orientaba hacia un desarrollo indiferenciado, se llego a que ese conjunto se orientara más bien hacia la liberación de las mayorias populares; donde se vivía con halagos de los poderosos de este mundo, se empezaron a sentir duramente - hasta el martirio y la constante amenaza de muerte- los rigores de la persecución por causa del reino.

El padre Amupe hizo posible todo esto porque, desde su enorme riqueza y libertad evangelicas, supo acercarse con autoridad y con humildad, con inmenso amor, a lo que ocurría por estas tierras. Muchos hechos pueden sefhalarse en esta línea que muestran su forma de gobierno patemal y evangélica, propia de un verdadero seguidor de Jesús dispuesto a dar la vida por sus ovejas y que realmente había venido a servir y no a ser servido. Cuando la universidad que dirigen los jesuitas en El Salvador sufrió las primeras explosiones de bombas contra ella por haberse puesto en favor de la reforma agraria $y$, consiguien- 
temente, en contra de los intereses oligárquicos. Amupe transmitió inmediatamente su apoyo y ayudó con cinco mil dólares a enjugar parte de los dafios. Cuando fue asesinado el jesuita Rutilio Grande por hacer pastoral entre los campesinos, ensentándoles a vivir y a comportarse como verdaderos hijos de Dios a quienes Jesús les había conquistado el don de la libertad, Arrupe quiso venir personalmente a apoyar a sus hermanos, aunque sus consejeros de Roma se to dificultaron por estimar que su vida corría peligro. Cuando triunfó la revolución nicaragüense, se trasladó a Managua para animar a los jesuitas en la evangelización de una nueva situación a la que no había que tener miedo por lo que tenía de auténticamente revolucionaria Cuando algunos jesuitas empezaron a ser objeto de acusaciones por sus escritos teológicos, Arrupe los llamo a Roma para medir por sí mismo, con calma, el espíritu que los animaba y, tras este examen cristiano, permitió que se abriesen en El Salvador los estudios teológicos para los jesuitas centroamericanos. Cuando se encontraba con quejas de otros eclesiásticos sobre las líneas pastorales de los jesuitas centroamericanos, llamaba a los responsables para conocer de primera mano sus puntos de vista, con lo que podía orientarlos mejor, animarlos y depositar en ellos su confianza. No era con espíritu de temor como gobernaba, sino con un espíritu de amor que despertaba en sus súbditos, a su vez, amor y obediencia.

\section{La vida religiosa en renovación}

Con todo ello logró una profunda renovación de la vida religiosa entre los jesuitas de Centroamérica, lo cual nos permite, desde una experiencia muy real, hacer unas cuantas reflexiones sobre el carácter más universal que sin duda tuvo como renovador no sólo de la vida religiosa de los jesuitas, sino también en buena medida de la vida religiosa en general. No sería exagerado decir que lo que Juan XXIII supuso para la renovación de la vida eclesial en general, lo ha supuesto el padre Arrupe para la renovación de la vida de los religiosos en particular. En ambos casos parece alentar el mismo espíritu, aunque en cada uno de ellos en forma distinta, pero con el mismo vigor. Quizá hoy, en un momento en que esa fuerza renovadora de la Iglesia en general y de la vida religiosa en particular se ve con algún recelo por los peligros que tiene - sin fijarse en lo que tiene de promesa de futuro-. conviene resaltar algunos puntos esenciales que hicieron posible y prometedora dicha renovación.

a) Ante todo, hay que ver la renovación como obra del Espiritu. Pocos, si es que hay alguno, se atreverán a dudar de la intensa y profunda espiritualidad del padre Arrupe. Otras cosas se habrán puesto en duda y aun bajo sospecha, pero difícilmente puede disimularse su recia y consistente espiritualidad. Esa espiritualidad es ignaciana por sus cuatro cosiados, aunque también lodos esos costados estaban abiertos, como la propia espiritualidad ignaciana lo exige, a las distintas novedades que el Espíritu va creando sobre la faz de la tierra No me toca a mí insistir, y menos analizar, cuáles son las características que la espi- 
ritualidad ignaciana adopta en la experiencia personal del padre Arrupe y en sus directrices como general de la Companía. Pero sí quiero subrayar el hecho de que fue en un largo proceso de profundización espiritual donde él buscó (y reclamó que los demás buscasen) la renovación de la vida religiosa.

Arrupe ha sido un hombre de Dios, por encima de codas las cosas; y queria que los jesuitas también lo fueran de verdad. Pero "de verdad". Este "de verdad" implica que era Dios a quien el buscaba, no cualquier otra cosa que quiera hacerse pasar por Dios, incluso entre ambientes religiosos y eclesiásticos. No sustituía a Dios por nada; un Dios más grande que los hombres; un Dios más grande que las Constiuciones y la estructura historica de la Companía de Jesús; un Dios más grande que la Iglesia y todas sus jerarquías; un Deus semper maior et semper novus, que sigue siendo el mismo, pero que nunca se repite; que necesita ser expresado en fómulas dogmálicas, pero que nunca es agotado en ellas. Un Dios, en definitiva, imprevisible por un lado, pero inmanipulable por otro. En la experiencia cotidiana de este Dios, al que dedicaba muchas horas de búsqueda, es donde se despertaba su gran libertad de espíritu, su gran amor a todos, su constante disponibilidad y humildad, y también su clarividencia religiosa. Una experiencia que, por una parte, era estrictamente trinitaria, como la de san Ignacio, pero que, sin dejar nunca de serlo, era también, por otra parte, siempre estrictamente cristológica y apegada a lo que es el Jesús histórico de los evangelios y el Jesús historizado de los Ejercicios Espirituales. Hombre de Dios, seguidor de Jesús, que no excluia otras mediaciones, pero que sabía subordinarlas a lo que es "principio y fundamento", a lo que es criterio último, a lo que, en definitiva, es fin y no medio. $Y$ en estas mediaciones quedan incluidas "todas las demás cosas creadas", que deben ser respetadas y utilizadas "tanto cuanto sirvan para el fin para el que el hombre es creado". La absolutización de cualquier cosa creada, por más sagrada y elevada que sea, por grande que sea la representación que ostente, no sólo en un pecado objetivo, sino que es un gran impedimento a la manifestación en la historia del Deus semper maior et semper novus. Contra esto pugnó el padre Amupe, aunque tal vez sus expresiones no fueran tan crudas ni sus actiondes tan agresivas, por cuanto sabia bien el respeto que merecen las mediaciones y el respeto que merecen las personas, que no se percatan de que están absolutizando en su práctica lo que dicen no ser absoluto en teoria.

b) Desde esta solidísima base -que no se tiene de una vez por todas, sino que, por su misma naturaleza, ha de renovarse día a dia-, Arrupe vivia abierto a la historia y, en la historia, a los signos de los tiempos. Hombre de Dios, pero también hombre de los hombres, hombre de la historia La novedad de Dios se percibe en gran manera en la novedad de la historia Las nuevas realidades plantean nuevas exigencias. No se trata de abandonar el pasado y sostener que cualquier pasado fue peor, pero tampoco se trata de repetir el pasado con pequeflas acomodaciones al presente, como si el presente actual de la humanidad y 
de su conciencia fuera tan sólo una pequefia novedad respecto de lo que esa misma humanidad y conciencia fueron no ya hace siglos, sino simplemente hace cincuenta afios. Se trata de discernir en los signos de los tiempos, tan nuevos y tan desaliantes, la voluntad de Dios; una voluntad que no es ajena a los hechos históricos. Pero, para discernir esos signos, es menester estar abierto a la universalidad del mundo. Muchos dicen estarlo; pero para ello se requiere no sólo mirar al mundo todo, sino, en lo posible, mirar desde todo el mundo. Y esto último es algo que no se hace, pero que Anupe intentó hacerlo de modo excepcional. El universalismo de Arrupe, ejercitado desde sus primeros aftos de madurez (al final de sus estudios en la Compaña), sometido a la ruptura cultural del oriente y, ya de superior general, cultivado generosamente, es un universalismo no tanto de objeto cuanto, sobre todo, de perspectiva. Veía el mundo desde Roma, pero también desde las naciones noratlánticas; y menos, pero también, desde las naciones sometidas al socialismo real. Y cada vez más, fue viéndolo desde las naciones del tercer mundo y desde los pobres de toda la tierra. Vefa el mundo desde la jerarquía eclesiástica, pero también desde los intelectuales, desde las culturas más diversas - él, tan preocupado por la inculturación, no sólc para encarnar la le, sino para que la fe se enriqueciera en esas sucesivas encamaciones-, desde las clases medias; pero sobre todo, y cada vez más, desde los más desprotegidos. La riqueza de este universalismo le ensefiaba la riqueza de Dios y le ponfa en mejor disposición para encontrar su voluntad.

c) Sobre esos dos fundamentos, el principal de los cuales era el propio Dios, pero cuyo correlato era el mundo en su historia, acab6 entendiendo el gran desafio del mundo actual. La evangelización, como anuncio de la buena nueva revelada en Jesús para que los hombres tengan vida y la tengan en abundancia, sigue siendo, en su formalidad, la misión principal de la Iglesia y, en ella, de los jesuitas. Pero esa evangelización tiene un destinatario principal, que son las inmensas mayorfas del mundo, a las que la vida les resula casi imposible, para las que el mero sobrevivir es la cuestión fundamental. De ah́ que aquella indicación tan simple como la de evangelizar a los pobres, aquella advertencia que ya Juan XXIII repetía de que la Iglesia debe ser, ante todo, una Iglesia de los pobres, se va a convertir en punto fundamental de la renovación de la Iglesia y de la vida religiosa A esta luz cobraba nuevas dimensiones aquella insistente y grave preocupación de san Ignacio por dar la espalda a los honores y riquezas de este mundo para abrazarse con la pobreza, las humillaciones y los sufrimientos que traen consigo el aprecio de éstos y el desprecio de aquéllos. Los jesuitas iban a dejar de ser los amigos de los ricos para convertirse en aliados y colaboradores de los más pobres. Esto no iba a hacerse sin costos, y Centroamérica los tuvo altísimos con el asesinato de los padres Grande y Alonso, los encarcelamientos, las expulsiones, las bombas, las constantes amenazas, los insultos y las difamaciones, los exilios... Pero, en contrapartida, un claro y consistente aumento de 
las vocaciones; una mucho mayor aceptación y credibilidad entre las mayorías populares y los movimientos progresistas, que antes nos velan como ajenos; $y$, sobre todo, un fuerte crecimiento en la fe, debido fundamentalmente a que la gracia de Dios se hacla presente de nuevo una vez más, especialmente entre los pobres, entre quienes habla prometido hacerse presente, realmente presente.

La evangelización y liberación de los más pobres, entendida no de un modo exclusivo (y menos aún de un modo que supusiera el fomento de la lucha de clases), sino entendida de modo "preferencial", cobraba un sentido estrictamente teologal, un sentido que tenía que ver directamente con Dios y con la donación de Dios a los hombres. Arrupe no era en modo alguno dualista en este punto, aunque algunas de sus manifestaciones escritas, en razón de la tradición en la que se habla educado doctrinalmente, pudieran hacerlo creer. La lucha en favor de la evangelización integral de las mayorias populares, a la que forzosamente pertenecia la lucha en favor de las mismas, era algo que tenía que ver directamente con Dios, al menos con el reino de Dios.

Lo que estaba ocurriendo en el mundo de hoy a la inmensa mayor parte de la humanidad no era un simple problema técnico y político de subdesarrollo y dominación; no era ni siquiera un problema puramente ético que desdijera de un ideal ético del hombre que pudiera fluir de su naturaleza racional; era más bien un problema estrictamente teologal, en el que estaba en juego la vida de Dios entre los hombres, Dios mismo entre los hombres. Por eso, no se trataba sólo de un fallo técnico y político ni sólo de una falta moral o una violación de los derechos humanos, sino que se trataba formalmente de un pecado que se enroscaba como una serpiente en el corazón del hombre, pero que al mismo tiempo se objetivaba y se hacía público en las pautas sociales, en las relaciones internacionales, en las instituciones políticas y, muy singularmente, en el orden económico internacional, que, so pretexto de libre intercambio entre las naciones y los grupos sociales, se constituye en el rostro agradable y encubridor de la explotación del hombre por el hombre.

d) La mision, entonces, era clara: ir preferencialmente a los pobres para, desde ellos y con ellos, evangelizar el mundo, liberar a la humanidad de todas sus cadenas, sin olvidar, ni mucho menos, las cadenas del pecado y las causas de las mismas. La vida religiosa volvla a entenderse desde la misión a que el rey eterno invila a sus fieles seguidores, pero teniendo muy en cuenta lo que es la bandera del "enemigo de natura humana" y lo que es la bandera de quien, "en suma pobreza" y en suma contradicción con los valores de este mundo, hace el llamamiento a seguirle. Se trata en ello de disposiciones interiores, pero tambien, "si asf lo quisiera su divina Majestad", de dejar en efecto lo que al mundo interesa y abrazar en efecto lo que Cristo sefialó como la forma humana de alcanzar lo divino, como la forma cirstiana de acceder a Dios.

La vida religiosa tenfa su centro fuera de sí; no era algo en y para si misma, 
sino que era algo en y para la misión. Pero no una misión abstracta para una evangelización abstracta, sino una misión y una evangelización que tenfan muy en cuenta la situación de nuestro mundo y que daban prioridad a lo que significaban las demandas de los más pobres. Este doble acento (el de poner la vida religiosa en función de la misión y el de entender la misión desde la opción preferencial por los pobres, sin olvidar en ningún momento lo que de más sólido y santificante tiene la espiritualidad ignaciana y el modo auténtico de proceder de los jesuitas) es la rafz de una auténtica renovación religiosa que busca a Dios y su voluntad donde mejor se puede encontrar; que busca lo que "más" conduce al fin para que fuimos creados, tal como ese fin y esos medios son iluminados por la vida de Jesús. Nada había en ello de no-ignaciano, aunque pudiera verse como poco "jesuítico", si por "jesuílico" entendemos todas las adherencias que el ambiente y los comportamientos áulicos y/o institucionales de la Iglesia y del mundo habian ido produciendo en la Compañía de Jesús so capa de buen sentido, de moderación y madurez, de buenas formas curiales y conventuales.

e) Volvió entonces a recuperar la vida religiosa su talante profético, y con ello un cierto sentido de confrontación no en todos los religiosos, pero si en buena parte de ellos e incluso entre los propios superiores, que por lo general habían estado más a cuidar de lo institucional que a fomentar la libertad y la creatividad del espfritu. Se llegó con ello, sobre todo en Latinoamérica, a una cierta confrontación entre los religiosos y la jerarquia; aquéllos, por lo general (junto con muy honrosas excepciones entre obispos y cardenales, que iban incluso en ocasiones por delante de los religiosos), eran más audaces y arriesgados, tanto en la búsqueda intelectual como en la praxis pastoral y en nuevos estilos de vida y hasta en nuevos ministerios; mientras tanto, la jerarquía se hacía más conservadora, más retenedora de lo antiguo y más temerosa del riesgo $y$ de la novedad.

Arrupe pretendio ser fiel a la jerarquía, pero sin que esta fidelidad derivada le impidiera alentar a quienes se sentlan llamados a arriesgar y a innovar. Propulsó toda suerte de experimentos, sin dejar que se perdiera nunca lo esencial (una profunda vida espiritual alimentada en mélodos y prácticas ignacianos; una gran seriedad en los estudios; un permanente discemimiento que iluminara, pero que no negara lo fundamental de la obediencia). El torbellino de la experimentación fue en ocasiones demasiado violento, y en su propio generalato llegó el momento de poner cautela a los experimentos y de asegurar ciertas líneas comunes. Pero no por miedo a la novedad y al riesgo, sino por buen juicio de no equivocar la actividad con la agitación, de no confundir el prurito de la novedad con la seriedad de la innovación. Podria decirse que en lo nuevo en cuanto nuevo vera Amupe algo divino, algo que muestra el Espíritu haciendo nuevas codas las cosas; pero sabía que no podía darse una novedad absoluta que rompiese con todo el pasado, en el que tambiên se había hecho presente el Espíritu de Jesús (y por lo que se refería a su propio caso y al de todos los 
jesuitas, especialmente en el san Ignacio de los Ejercicios y de las Constituciones). Difícil tensión ésta entre lo nuevo y lo viejo, entre lo espiritual y lo institucional, entre la tradición que viene de atrás y la profecía que mira hacia adelante, entre la obediencia a Dios y la obediencia a los hombres. Esta tensión fue la que le causó dificultades con muchos estamentos jerárquicos y la que le originó los mayores disgustos con la Santa Sede, mientras eran numerosísimos los obispos, superiores religiosos, té́logos y pastoralistas que vefan en él un signo de los tiempos y una luz alentadora de empresas eclesiales siempre nuevas, siempre audaces, incapaces de buscar el reposo antes de haber recorrido el largo camino de la experimentación, la escucha de las necesidades del mundo y la respuesta desde el evangelio.

Esta tensión entre el carisma de la vida religiosa y la vigilancia más institucional de la jerarquía ha sido permanente en la Iglesia a lo largo de su historia, y ha sido fructífera la mayor parte de las veces. Pero esto se reconoce más tarde. En el momento del conflicto se admite con dificultad lo valioso del carisma y se tiende a recortarlo en beneficio de la seguridad de lo institucional. Algo de esto ha ocurrido en el caso del padre Arrupe, lo cual es una prueba más de que realmente se ha dado en él una poderosa y auténtica innovación de la vida religiosa. El poder no quiere riesgos y se aferra al pasado como garantía permanente. Pero el aggiornamento ya había sido lanzado en el Vaticano II, y el propio Juan XXIII, que unía en sí lo institucional y lo carismático, lo viejo y lo nuevo, la fidelidad al pasado y la fidelidad al futuro, había sido un buen modelo de lo que la Iglesia necesitaba en aquel momento. El vendaval descuajó, dentro y fuera de la Companfa - a veces se cometen tremendas injusticias con el generalato del padre Amupe, como si sólo la Companta de Jesús hubiera sufrido perdida de vocaciones antiguas y nuevas-, árboles de gran envergadura y, desde luego, hizo caer por los suelos rarnas más o menos secas.

f) Pero nada de esto impedía que la vida religiosa siguiera siendo vida en comunidad. La vida comunitaria no es en la vida religiosa un fin en sí misma ni es tampoco un puro medio; es, más bien, una parte integrante de ella. Pero se ha propendido a entender la vida comunitaria como si se redujera a una comunidad de bienes, a una comunidad de obediencia y a una comunidad de ordenamientos externos. Hacer todas las cosas al mismo tiempo, conforme a un "orden del dia", se tomaba por "vida en común"; el estar sometido a unos mismos reglamentos se consideraba lo esencial de la vida comunitaria. Esto daba lugar a vidas paralelas, más que a vidas comunitarias; a la comunicación de lo exterior, más que a la comunicación de lo interior: algo muy alejado de poner la vida en común y de hacer buena parte dela vida en común, donde "vida" ya no es la practica exterior, sino aquello que fundamentalmente hace el hombre.

Ciertamente, Arrupe no es un dualista, ni es tampoco un despreciador de aquellas cosas extemas que ayudan a ordenar la vida en común. Pero mucho 
menos es un reduccionista que tenga por vida en común lo que no es vida y lo que no merece la pena ser comunicado. No confundia el fondo con la forma ni lo esencial con lo accidental; y mucho menos hacía cuestión máxima de lo que es mínimo y mínima de lo que es máximo. Incluso en actos al parecer tan solitarios como su misa diaria en su pequefia "catedral" (de la que existen espléndidos testimonios personales), él se esforzaba muy vivamente por estar en comunidad real con lodos los jesuitas a él encomendados. No se sentia solo; estaba alli para comunicar y para recibir, para dar y para aceptar. Lo que era "misión" en su concepción de la vida apostólica era "comunicación" en su concepción de la vida comunitaria. Pero era más feliz dando que recibiendo, a pesar de su inmensa humildad de superior que a todos pregunlaba para enriquecer sus propios puntos de vista. Fue asi, con su ejemplo, con sus directrices y exhortaciones, un gran renovador de la vida comunitaria, impulsando los discernimientos comunitarios y la eucaristía en común, donde lo importante no era estar materialmente juntos, sino espiritualmente comunicados, abiertos a la escucha y a la corrección, prontos a dar lo mejor de uno mismo, pero siempre desde la perspectiva de la misión apostólica, del hacer bien a los demás, de la evangelización. La verdad de la vida comunitaria debia contrastarse con lo que era el trabajo apostólico, que, cuanto más arduo y peligroso, más necesidad tenía de intensa vida comunitaria $y$, sobre todo, de estrecha relación del hombre con Dios. La comunidad, no obstante, debia constituirse en lugar privilegiado, en mediación excepcional de esa estrecha relación, que podía verse sometida a autoengaño sin el contraste comunitario.

g) Nada de esto anulaba tampoco el valor y la necesidad de la autoridad y la obediencia, sino que situaba ambas en su exacto lugar. Tal vez en este punto fundamental del modo cristiano de ejercer la autoridad y de animar a la obediencia es donde -quizá más con el ejemplo que con grandes disquisiciones léricas o con normas de gobiemo- da el padre Amupe un mayor impulso a la vida religiosa. No puede desconocerse el hecho de que un buen grupo de jesuitas (los más conservadores y los más opuestos al cambio) opuso fuerte resistencia a la autoridad del padre Arrupe y fue buscando escapatorias teoricas y procedimientos prácticos para evadir el cambio que había suscitado el Vaticano II y que Amupe, junto con otros procuró que se viviese de modo especial en la vida religiosa Los que tenfan la mirada puesta atrás no comprendieron fácilmente el nuevo numbo, pero s! lo hicieron los que miraban hacia adelante. Por eso no debe considerarse a Amupe como un conservador de las formas antiguas de la vida religiosa, sino como un profundo renovador, al que el futuro dara la razón y sabrá medir con equidad. No es que siguiera el gusto de unos y se opusiera a los modos de otros. A quienes ansiaban la renovación como una necesidad imperiosa, también los sometió a prueba y no dejó que campasen por sus respetos. Pero, en general, éstos aceptaron su autoridad e interiorizaron sus orientaciones. 
Sin entrar en detalles, conviene tal vez detenerse en este punto esencial para la vida de la Iglesia y para la vida en la Iglesia de los religiosos: el ejercicio de la autoridad. En este punto, Arrupe es mucho más ejemplar como superior que como súbdilo, en parte porque sus esquemas té́ricos y su antigua práctica le llevaban a posiciones menos crealivas en el modo de ser súbdito. Por eso vamos a insistir un poco más en su modo de ser superior, del que se desprendía un nuevo modo de ser súbdito.

Dicho brevemente: Arrupe ejercía la autoridad de un modo evangélico. Suelen decirlo muchos superiores, pero no son tantos los que lo ponen en práctica Podría asegurarse que tenía del todo presente el mandato evangélico de no ejercer la autoridad en la Iglesia como se ejerce en el mundo: los jefes de los pueblos los tiranizan, y los grandes los oprimen; pero, entre los discípulos, el que vaya a estar arriba y haya de actuar como primero, ha de ser servidor y esclavo, porque el Hijo del hombre no ha venido a ser servido, sino a servir y a dar su vida en rescate de Arrupe ejercía su ministerio de superior —real, efectiva y afectivamente- como quien sirve hasta dar su vida por los demás. Ambas notas son características de él, y en su unidad muestran el ideal cristiano de la forma de ser superior: no sólo dar la vida, sino darla como quien sirve; no sólo servir, sino servir dando la vida; jamás aprovechar la condición de superior para ser alabado, para ser servido, para estar delante de los demás. Esto, junto a su capacidad profética y su don de comunicación y de animación, hizo que los superiores generales de otras Ordenes le eligieran reiteradamente, hasta el último momento, presidente de la Unión de Superiores Generales.

Como superior general, daba directrices y buscaba que se cumplieran; daba ordenes, a veces dolorosas, y exigía su cumplimiento. Pero, con anterioridad, no sollo escuchaba a quien quería representarle otro punto de vista, sino que llamaba paternalmente para que la orden en cuestión surgiera como resultado de un conocimiento iluminado. No había entonces tanta dificultad en obedecer, y no porque la orden pareciera siempre buena o la mejor, sino porque la forma de encontrar la voluntad de Dios, la forma de mandar, era buena, era conforme al espíritu del evangelio. Lo cual hacía que, con el tiempo, pudieran cambiarse sus decisiones, porque no se consideraba infalible ni tenia miedo a perder autoridad. Sabia que quien quiere ser el primero en el reino ha de situarse con los últimos, para que sea el Seffor, no los hombres, quien lo invile a subir más cerca de él.

No deja de ser significativo de este espíritu el hecho de haber sido el primer general de la Companía de Jesús que, en pleno uso de sus facultades, ha pretendido presentar su renuncia. Sólo lo ha hecho un papa en la Iglesia, y sólo lo ha hecho el padre Arrupe en la Companía. Creen algunos que su renuncia vino forzada por la enfermedad. No es así. Arrupe había querido preparar una congregación general para presentar ante ella su renuncia al generalato. Juan Pablo 
II se lo impidió, y en el intervalo se desató el fulminante ataque cerebral, al regreso de un viaje a Filipinas, adonde había ido, como superior, a conocer mejor la vida de sus súbditos, a escuchar sus problemas, a animarlos en sus empresas, a estar con ellos en medio de la persecución. En sus viajes como superior, el padre Arrupe escuchaba muchísimas horas, con lo que sus palabras ya no eran palabras traídas de fuera, sino respuesta a los problemas y a las preguntas que se le presentaban antes y durante el mismo viaje.

Nada de esto iba en detrimento del sacrificio que es propio de la obediencia, pero sí hacía que dicho sacrificio, como el de la fe, fuera un "obsequio" razonable. No era sólo cuestión de liderazgo, que sin duda lo tenía Amupe en grado elevadísimo; no era sólo cuestión de simpalia y de amabilidad, que eran en él excepcionales; no era sólo cuestión de modestia y de humildad; no era sólo cuestión de inmenso respeto por las personas y de liarse de ellas a veces hasta preferir ser enganaado que desconfiado; era, sobre todo, un modelo de ejercer la autoridad de forma específicamente cristiana y no al modo como lo hacen los sefiores mundanos, lanto fuera como dentro de la Iglesia. La obediencia cristiana a los que presiden en la Iglesia, cualquiera que sea su forma de presidencia, poco o nada tiene que ver con la sumisión que puede tenerse a los que dominan en este mundo. Es, sencillamente, otra cosa; porque la autoridad en la Iglesia es un servicio al pueblo de Dios, no un privilegio. Hacer de la obediencia religiosa una obediencia cristiana, y de la autoridad religiosa una autoridad cristiana, fue uno de los empeños importantes en la renovación de la vida religiosa por parte del padre Amupe.

No es facil encontrar la voluntad de Dios, que es la finalidad fundamental de la obediencia, porque, aun cuando pueda mantenerse que es voluntad de Dios el obedecer en determinadas circunstancias, no es evidente, sin más, que lo mandado sea siempre voluntad de Dios. También compete al súbdito una gran responsabilidad, no delegable, en el encuentro de la voluntad de Dios, tal como se ve manifiestamente en los Ejercicios Espirituales de san Ignacio, con su propia lógica existencial, de la que hablaba un gran teólogo y admirador de Amupe: Karl Rahner. El superior no puede encontrar por sí solo la voluntad de Dios, y haría muy mal en imponerla como tal si no ha cumplido con todas las condiciones necesarias para hallarla. No hay contacto directo del superior con Dios que garantice el encuentro de su voluntad, que es en sí misma libre y, por lo tanto, no deducible de principios absolutos. Habrá que llegar finalmente a una decísión que será vinculante en los casos ordinarios, incluso contra el parecer de muchos; pero el mandato como tal sólo será cristiano, al menos en su cotenido, si se ha dado conforme a las garantias que el evangelio exige. Arrupe era exigente en la teoria y en la practica por lo que hace a la obediencia; no era muy partidario de la objeción de conciencia cuando esta se convierte en recurso ordinario para no obedecer, pero si era sumamente cuidadoso en mandar al estilo de Jesús, en hacer más caso al espiritu que a la letra, en preferir la gracia a 
la ley, en optar por el impulso antes que por la coacción, en hacer de la obediencia religiosa una obediencia formalmente cristiana, lo cual la hace más humana, pero no por ello mundana. La mundanidad de la autoridad y de la obediencia, su secularización, no viene de abandonar el autoritarismo vertical; viene más bien de perder de vista las exigencias evangélicas; viene de la contaminación; viene de querer anular la liberad de los hijos de Dios en aras de un más fácil gobiemo institucional. Sin caer en idealismos románticos, sin descuidar la profunda tradición ignaciana, Amupe instauró una nueva forma de mandar y de obedecer. Fue éste uno de los puntos en que no llego a hacerse comprender por todos, especialmente por aquellos cuyo carisma de mandar evangélicamente no era muy señalado. Al no mandar como los sefíores de este mundo, sino como un discípulo de Jesús, se creyó que eslaba desvirtuando la obediencia, cuando estaba renovándola y santificándola; cristianizándola de nuevo, en suma.

h) Arrupe estaba también persuadido de la vigencia de la vida religiosa en el momento actual y para el futuro. Estaba persuadido de que la vida religiosa era indispensable para la sanuficación de muchos cristianos con esa concreta vocación, para que la fe y la gracia resplandecieran en toda su fuerza, para que la Iglesia pudiera cumplir mejor con su misión santificadora y evangelizadora, pero también (y no en último lugar) para que el mundo fuera realmente más humano, a ta vez que más divino. A pesar de las sacudidas que el desaffo y la libertad del Vaticano II, junto con la imupción de los valores del mundo en la conciencia actual, causaron en distintas órdenes y congregaciones religiosas, no excluida la Companía de Jesús, el padre Arrupe no dudó de la vitalidad de la vida religiosa ni de su enorme utilidad, siempre que se renovara como lo exigía el Concilio y como lo demandaba la nueva realidad histórica y su conciencia correspondiente. Segula pensando - y así lo iba transmitiendo por dondequiera que iba- que la vida religiosa ofrecía las máximas posibilidades para la realización del reino de Dios entre los hombres, que incluye tanto la presencia salvílica de Dios entre ellos como la realización de un mundo conforme al designio de Dios.

Visto el problema desde América Latina, donde la vida religiosa tiene una preeminencia cuantitativa y cualitativa innegable sobre otros sectores de la Iglesia, esa actualidad y esa promesa de futuro es aún más viva y evidente. El padre Amupe, que veía en la Iglesia de América Latina una auténtica reserva para la Iglesia universal (por la importancia numérica de los bautizados; por la unidad de loda ella en una misma fe; por los pobres que en ella misma viven, y que por ese mismo hecho la situan entre los preferidos de Dios; por la generosidad con que ha dado verdaderos mártires por la causa de la justicia), pensaba que toda ella $-y$, dentro de ella, especialmente los religiosos - tenía un gran porvenir y una enorme responsabilidad.

Ese porvenir y esa responsabilidad pueden formularse en términos de li- 
beración, tal como ésta es entendida por la verdadera teología de la liberación latinoamericana. No olvidemos que el padre Arrupe asistió a la asamblea del episcopado latinoamericano en Medellín (1968), donde se hizo vigorosamente presente y fue gozosamente aceptada por la mayoría de los obispos latinoamericanos la teología de la liberación; y asistió también a la siguiente asamblea, la de Puebla (1979), donde ya empezaba a combatirse a la verdadera teología de la liberación so pretexto de algunos posibles excesos que se habían cometido en su nombre. Ciertamente, Amupe no llegó a conocer a fondo la teología de la liberación, aunque sí leyó algunos libros significativos dentro de esta corriente. Su impresión era que dicha teología estaba aún por hacer; pero animaba a hacerla, porque apreciaba su importancia y la objelividad con que estaba siendo elaborada, aparte de que conocía a algunos de los que la cultivaban creativamente y buscaban con toda seriedad dar a su esfuerzo una profundidad verdaderamente teológica y científica. Pero, aunque no conociera a fondo esa labor teológica, sí participaba muy intensamente de la vivencia cristiana de la que ha surgido la necesidad de dicha teología. Muchísimas de sus palabras y acciones lo demuestran; tanto que no es necesario insistir en ello. No era amigo de exageraciones ni parcializaciones; pero los postulados fundamentales de la opción preferencial por los pobres, de la causa de la justicia, de la liberación integral, los tenía muy en su corazón y orientaban muchas de sus decisiones. Insistía en que era muy necesario sentir la pobreza en contacto con la vida de los más pobres, llevando en lo posible su misma vida, al menos durante algunos períodos, insistía también en que las obras apostólicas de la Compantía reflejaran lo que exige la evangelización y liberación preferencial de los más pobres y necesitados.

Pero insitfa igualmente, eso sf, en que la liberación fuera integral. Afimaba que no se trata sólo de una liberación política y económica, pero subrayaba que esta liberación econónica y politica era parte de la liberación total, de la que es elemento necesario. Esa liberación debla extenderse a la liberación del pecado, de todo pecado, tanto personal como institucional y estructural; y debe extenderse también a la liberación de las ralces del pecado en el hombre, como son el egolsmo, los fdolos de la sociedad de consumo y de la sociedad técnica, que han suscitado en el hombre la concupiscencia del dinero y del poder, el desbordamiento de la sexualidad, el deseo de dominación y tantas otras idolatras que tienen que ver con la libertad cristiana interior, pero también con la creación de un mundo en el que sea posible, junto con la justicia, el máximo de liberiad y la anulación de loda forma de dominación y de exclavitud.

Dos delicados problemas se le plantearon a Amupe respecto de los procesos reales e históricos de liberación: el uso de la violencia y el uso del análisis (y su consiguiente praxis) marxista.

Respecto de la violencia, Arrupe se mantuvo en la afirmación de que habia que tratar de evitarla, porque en principio no es evangélica; por ello no estaba de acuerdo en que los religiosos se hiciesen sujetos activos de la lucha armada. 
Respecto al uso del análisis marxista, su juicio fue mucho más matizado: reconociendo los peligros que habla en dicho uso, su rechazo del mismo no es total y absoluto, como lo demuestra una lectura cuidadosa de su instrucción sobre este punto, sobre todo si tenemos en cuenta la consulta previa que la preparo y las dos redacciones, al menos, que tuvo. En ese escrito y en directrices más particularizadas, se evitan los simplismos del "blanco o negro", de la aceptación ingenua o del rechazo dogmálico. Por lo que hace a la praxis marxista estrictamente política, su rechazo era mayor, sobre todo cuando dicha praxis implicaba, más que una lucha de clases, un odio de clases que condujera a la violencia - cosa que tiene muy poco que ver con el marxismo científico- y cuando conllevaba una afiliación política, con la que no estaba de acuerdo y que trataba de impedir con prudencia, pero también con firmeza.

Seria exagerado afirmar que Arupe presentaba el futuro de la vida religiosa exclusiva o predominantemente en términos de "liberación", tal como ésta se entiende en algunas partes del tercer mundo, y muy especialmente en buena parte de la Iglesia latinoamericana. Su universalismo y su afán de totalidad equilibrada lo hacían ver también las peculiares riquezas de Africa, del oriente y hasta de los países noralánticos. Pero lo menos que se puede decir es que estaba muy abierto a la peculiaridad historica de América Latina, y que planteaba un ideal de vida religiosa que es perfectamente conciliable con lo que sobre dicho upo de vida y su espiritualidad han mantenido los mejores teólogos de la liberación. Para que la liberación fuera integral, se debla atender a lo personal y a lo estructural, a lo espiritual y a lo material, a lo inmanente y a lo transcendente. Todo ello, en una perfecta unidad que ni confunde ni separa, es muy propio de la vida religiosa y de la mejor tradición jesuítica. Las "reducciones del Paraguay" podrian constituir un modelo de esta totalidad y esta armonía, por más que los tiempos exijan hoy otras formas de realizar el mismo propósito.

Arrupe no era un "espiritualista" ni reducía el papel de los religiosos a dar testimonio de la transcendencia de la fe, dejando para los seglares las tareas que se llaman "terrenas". Esto iría contra toda la tradición de la vida religiosa, desde san Benito hasta san Ignacio. Una cosa es dejar el poder político a los políticos - cosa que no se ha hecho siempre entre eclesiásticos y religiosos-y otra muy distinta es abandonar el campo de las mal llamadas "realidades terrenas" a los laicos, como si los religiosos y los sacerdotes no tuvieran, aun respetada su especificidad, que comprometerse con este mundo, o como si tuvieran que separarse de él, como hicieron los esenios. No fue ese el modelo de Jesús, ni lo ha sido tampoco el de la gran tradición religiosa, excluidas tal vez, de alguín modo, las grandes órdenes contemplativas. Sin la vida religiosa, la liberación integral de los más pobres quedaría privada de una de las fuerzas potencialmente más efectivas, precisamente por lo que representan de unidad entre to divino y lo humano. 
Concluyamos ya este argumento de Arrupe como gran renovador de la vida religiosa. Muchas más cosas podrían decirse y, sobre todo, podrían estudiarse sus escritos sobre este tema para poder perfilar, desarrollar, fundamentar y ampliar lo que aquí se ha dicho. El método seguido ha sido otro: mostrar cómo se veía la acción del padre Amupe, por lo que se refiere a la vida religiosa, desde esta perspectiva peculiar que es la de Centroamérica en algunos de los años más difficiles de su historia. La elección no ha sido arbitraria. Arrupe puso mucho corazón y mucho discernimiento en los problemas de Centroamérica. No en vano, los jesuitas fueron perseguidos en esta región de manera muy especial; porque ya no eran los marxistas y los ateos los que ponían en dificultades a los jesuitas, sino regimenes y clases sociales que se decían "cristianos". Los dos jesuitas asesinados y otros muchos perseguidos y amenazados, violentados de tantas formas, hacian que su comprensión y su preocupación fueran mayores.

Por otro lado, el aparente particularismo que puede ofrecer esta perspectiva queda superado por la riqueza y la radicalidad que desde ella se alcanzan. No en todas partes se pide lo mismo hoy de la vida religiosa; pero si no aparecieran, en la forma que fuere, algunos de los aspectos que aquí se han tratado, no sólo podría decirse que se está olvidando y desviruando el gran aporte de Arrupe a la vida religiosa, sino que (lo que es más grave) se estaría impidiendo la renovación misma de la vida religiosa y, con ello, lo que ésta puede aportar a la salvación y liberación de los hombres. 